\title{
WestVirginiaUniversity
}

THE RESEARCH REPOSITORY @ WVU

Graduate Theses, Dissertations, and Problem Reports

2012

\section{Factors Affecting Orthodontic Adherence In Appalachia}

Breana M. Phillips

West Virginia University

Follow this and additional works at: https://researchrepository.wvu.edu/etd

\section{Recommended Citation}

Phillips, Breana M., "Factors Affecting Orthodontic Adherence In Appalachia" (2012). Graduate Theses, Dissertations, and Problem Reports. 3338.

https://researchrepository.wvu.edu/etd/3338

This Thesis is protected by copyright and/or related rights. It has been brought to you by the The Research Repository @ WVU with permission from the rights-holder(s). You are free to use this Thesis in any way that is permitted by the copyright and related rights legislation that applies to your use. For other uses you must obtain permission from the rights-holder(s) directly, unless additional rights are indicated by a Creative Commons license in the record and/ or on the work itself. This Thesis has been accepted for inclusion in WVU Graduate Theses, Dissertations, and Problem Reports collection by an authorized administrator of The Research Repository @ WVU. For more information, please contact researchrepository@mail.wvu.edu. 
Factors Affecting Orthodontic Adherence In Appalachia

\author{
Breana M. Phillips, B.S.D.H., M.S.D.H. Candidate
}

Thesis submitted to the West Virginia University School of Dentistry, Department of Dental Hygiene in partial fulfillment of the requirements for the degree of

\author{
Master of Science \\ in \\ Dental Hygiene
}

\author{
Chris Martin, D.D.S., M.S., Chair \\ Daniel W. McNeil, Ph.D. \\ Richard Crout, D.M.D., Ph.D., M.S. \\ Amy Funk, M.S.D.H.
}

Division of Dental Hygiene

Morgantown, West Virginia

2012 


\section{Copyright 2012 Breana M. Phillips}

\section{Abstract \\ Factors Affecting Orthodontic Adherence in Appalachia}

\section{Breana M. Phillips}

Orthodontic intervention enhances not only esthetics and psychosocial health, but also improves the function of the human dentition. Many insurance programs now offer orthodontic coverage; however, proper adherence and good oral hygiene habits are poor among those Appalachian individuals undergoing orthodontic care. This research study was conducted to determine the contributing factors in poor orthodontic compliance in Appalachia. Investigators completed a retrospective chart review, assessing inactive orthodontic patients from 2007-2012 at a private practice in North Central West Virginia. The general dentist at this rural office practices both general dentistry, as well as, orthodontics. Information regarding demographics, form of payment, and distance traveled was collected. Data analysis using these variables was conducted. Statistical analysis included, but was not limited to a Chi Square Fisher's Exact Test, One-way ANOVA, and logistic regression. The results of this study demonstrate that there is significant difference in completion rates based on payment type among Northern Appalachian orthodontic patients. The results also demonstrate that treatment length and oral hygiene ratings are associated with completion rate. The findings validate that psychoeducational interventions may be needed to address these disparities in orthodontic patients of Appalachia. By encouraging oral heath values and requiring appointment adherence, an expected outcome will be the improvement of orthodontic completion rates in Appalachia. 


\section{Acknowledgements}

The author would like to express recognition and appreciation to many individuals from West Virginia University School of Dentistry who made this research possible.

Chris Martin, D.D.S., M.S., Department of Orthodontics, Thesis Committee Chair, for giving his time, support, and guidance. Dr. Martin's reliability and excitement in this project is greatly appreciated.

Daniel W. McNeil, Ph.D., Department of Psychology, for his valuable advice and expertise.

Amy Funk, M.S.D.H, Division of Dental Hygiene, for her assistance and motivation.

Richard Crout, D.M.D., Ph.D., M.S., Department of Research, for his enthusiasm in research and collaboration with this research.

Gerry Hobbs, Ph.D., Community Medicine, Department of Statistics, for assisting in the data analysis for this project.

Dr. Sonya James, D.D.S., for her permission to complete research within her practice. Her participation has allowed our committee to create significant conclusions regarding orthodontic care among Appalachian patients. 


\section{Table of Contents}

Title

Abstract

Acknowledgements

Table of Contents

Introduction

Purpose of the Study

Statement of the Problem

Significance of the Study

Hypotheses

Definition of Terms

Review of Literature

Methods and Materials

Results

Discussion

Limitations \& Recommendations

Conclusions

Bibliography

Appendices

Appendix A: Chart abstraction form

Appendix B: List of code descriptions

Appendix C: Excel spreadsheet example

Tables and Figures i

ii

iii

iv

1

2

3

3

4

4-5

6-13

13-15

16-17

17-20

20-21

21-22

23-28

29

30-31

32

$33-40$ 


\section{Introduction}

Utilization of oral health care services in West Virginia is extremely poor, as demonstrated by the fact that in 2006 the state had the greatest proportion of edentate people of any state of jurisdiction in the nation, and it was one of the states with the fewest annual oral health care visits. ${ }^{5}$ Cultural views on malocclusion and other psychosocial factors are known to influence the demand for orthodontic treatment. ${ }^{16}$ Certainly, social norms in West Virginia and other areas of Appalachia contribute to oral health values, perhaps based in part on less recognition of the importance of maintaining the natural dentition and a lower desire to change the occlusal status of one's anterior (and other) teeth. ${ }^{20}$

Medicaid and the Children's Health Insurance Program (CHIP) are major sources of free dental coverage, reaching millions of low-income children, but inadequate access to oral health care among these children remains a critical health policy challenge. ${ }^{24}$ The programs provide quality health insurance to eligible children and strive to develop a health care system in which all West Virginia children can access health care coverage. The service benefits include orthodontic treatment coverage in adolescents meeting the specific criteria developed by Medicaid and CHIP.

Conclusions have been made that poor dental treatment is related to the low number of dentists participating in these programs. Many dentists that do participate often limit the number of Medicaid and CHIP patients they accept. ${ }^{26}$ However, minute concentration has been made on the association of poor orthodontic outcomes in adolescents utilizing these free dental programs. Moreover, little conclusions have been made regarding poor orthodontic completion rates, as well as, poor oral hygiene compliance among the Appalachia population. 


\section{Purpose of the Study}

The purpose of this retrospective study is to improve our understanding of the barriers to successful orthodontic outcomes in patients of Appalachia. Understanding the reasons for poor oral hygiene compliance, appointment adherence, and parental agreement is critical for clinicians and researchers. To better understand the factors and implications of poor orthodontic outcomes, the specific aims of the project are:

Aim 1: To examine the relationship between dental priority of patient and parents and orthodontic completion rates among the Appalachian population. Using inactive orthodontic patients, our working hypothesis is that lack of dental priority is positively correlated with low completion rates. By abstracting the reason for early-ending treatment, it is anticipated to correlate parental and patient priority to completion rates in the Appalachian population.

Aim 2: To determine the impact of oral hygiene compliance on completion rates of orthodontic patients in Appalachia.

Aim 3: To find the correlation between the variables of demographic information, payment type, length of travel, and treatment length with poor orthodontic outcomes. 


\section{Statement of the Problem}

Poor patient compliance has major implications in the results of orthodontic treatment and oral health. With non-compliance in oral hygiene and missing much needed appointments often results in the occurrence of hyperplastic gingivitis, enamel

decalcification and white spots, periodontal breakdown, and carious lesions. ${ }^{11}$ Continual non-compliance issues may jeopardize the success of orthodontic treatment. This study will be conducted to identify the level of compliance of Appalachia patients who underwent orthodontic treatment at a private dental office in rural, North Central West Virginia.

\section{Significance of the Study}

The long-term objective of this project is to improve our understanding of the factors affecting orthodontic compliance in the patients of Appalachia. Abstracting demographic, psychosocial, behavioral, and clinical information will be completed to accomplish this goal. Ultimately, the project will generate the differences between compliant and non-compliant patients and discuss improvements that can be made to increase the completion rate in orthodontic patients. 


\section{Hypotheses}

1. There is significant difference in completion rate among the three payment groups; private insurance, self-pay, and government funded Medicaid/CHIP.

2. There is significant difference in completion rate and oral hygiene ratings.

3. There is correlation between completion rate and length of orthodontic treatment.

4. Completion rate and distance traveled are inversely related.

\section{Definition of Terms}

- Appliance

O Upper Arch "Braces" - bands, brackets, and wires on upper arch of teeth

O Lower Arch "Braces"- bands, brackets, and wires on lower arch of teeth

O Full (both) Arch "Braces"- bands, brackets, and wires on both arches

$\bigcirc$ Device - a fixed appliance to assist in the movement and alignment of the jaw, arches, and/or teeth

- Occlusion - Relationship between the maxillary (upper) and mandibular (lower) teeth.

- Malocclusion - Misalignment of teeth or incorrect relation between the teeth of the two dental arches.

$\bigcirc$ Class I - Defined as the upper and lower first permanent molars are related so that the mesiobuccal cusp of the upper molar occludes in the buccal groove of the lower molar. Considered the "ideal" relationship between the upper and lower teeth. Crowding or spacing may be present with a Class I bite.

O Class II - Defined as the lower molar distally positioned relative to the upper molar. Commonly known as an "over-bite." The two divisions describe the position of the anterior (front) teeth.

- Division I - Maxillary anterior (upper, front) teeth protrude.

- Division II - Maxillary anterior (upper, front) teeth retrocline with flaring of the upper lateral incisors.

O Class III - Defined as the lower molar mesially positioned relative to the upper molar. Commonly known as an "under-bite."

- Oral Hygiene Index $(\mathrm{OHI})-\mathrm{An}$ index that measures the current oral hygiene status based on the amount of debris and calculus present in the mouth. 
O 1: Good oral hygiene; Represents minimal amount of plaque; less than $25 \%$ of deposit covering the teeth.

○ 2: Fair oral hygiene; Represents moderate amount of plaque; more than $25 \%$ but less than $50 \%$ of deposit covering the teeth.

O 3: Poor oral hygiene; Represents an abundance of plaque; more than 50\% of deposit covering the teeth.

- Treatment

O Band/Bond - Process of cementing and attaching brackets and bands to the teeth.

O Broken Appointment - Not showing up for a scheduled visit.

O Cancelled Appointment - Cancelling a scheduled visit by phone.

O Cement Removal - Removal of excess cement from the teeth, that was holding appliances in place.

O Deband/Debond - Process of removing the bands, brackets, wires, and/or devices from the teeth.

O Device Adjustment - Adjustment completed by an orthodontist to assist in the alignment and correction of the jaw, arches, and/or teeth.

O Ligature Retie - Process where the arch wires are adjusted or changed and "retied" to the bands and brackets.

O Records - Initial assessment which includes radiographs (x-rays), impressions, and photographs extraorally (outside the mouth) and intraorally (inside the mouth)

O Separator Placement - Process in which elastic rubber bands are placed between teeth to create space for band placement. Commonly known as "spacers". 


\section{Review of Literature}

Facial aesthetics have been suggested as one of the most important variables in terms of an individual's own self-esteem and social acceptance. As facial appearance changes from childhood to adulthood, it has a great impact on an individual's

psychology. ${ }^{17}$ Patient compliance is not only limited to appliance wear, but it also includes the daily tasks of oral hygiene procedures, proper caring for orthodontic appliances and keeping routine scheduled appointments on time. It is essential to have a very good patient cooperation in order to reach esthetic goals and to ensure that the patient gets a pleasing result at the end. A patient's non-compliance can result in a longer treatment time, destruction of the teeth and periodontium, extraction of additional teeth, collapse of a corrected malocclusion after treatment, frustration for the patient and additional stress for the orthodontist and staff. ${ }^{4}$

It is estimated that five to ten percent of orthodontic patients do not complete treatment due to poor oral hygiene. ${ }^{11}$ Moreover; compliance rates of long-term treatments have been reported to be as low as fifty percent. ${ }^{26}$ To prevent adverse effects due to noncompliance, many studies have identified multiple demographic, psychosocial, psychological, and behavioral factors to predict compliance. ${ }^{13}$ Factors reported as associated with compliance include patient characteristics (e.g., mental and physical disabilities, beliefs and attitudes, history of noncompliance, parental influence); treatment complexity and duration; the relationship between the patient and provider; and educational and behavioral interventions used. ${ }^{10}$ Orthodontic treatment experience during the initial visit has also been considered a predictor for future compliance. ${ }^{13}$ 
The primary causes for poor cooperation have been attributed to pain, functional, and aesthetic impairment caused by the appliances. This has even resulted in a discontinuation of treatment or its early termination. The literature suggests that the patients' initial attitude towards orthodontics should be understood during the diagnostic phase itself and should be discussed with the patients in all its reality. ${ }^{21}$ The psychosocial variable intervening between need versus demand for treatment is an affective domain, which includes the emotions regarding whether or not the individual wishes to seek orthodontic treatment. Dissatisfaction with one's dentofacial appearance, recommendations from a dentist, concern on the part of parents and the influence of schoolmates who wear braces are among the main factors directly involved in the demand for orthodontic treatment. ${ }^{3}$

Gender, age, intellectual level, social class, severity of the malocclusion, dental care and self-perception of facial aesthetics have also be found to be associated to the desire for orthodontic treatment. Patients who seek orthodontic treatment are undoubtedly concerned with improving their appearance and social acceptance. Thus, enhancing these aspects may be important to public healthcare. ${ }^{14}$ Beliefs reflect the influence of age, gender, ethno-cultural and socioeconomic variables determining personal values in changing the facial morphology. ${ }^{18}$ Results of a study in Australia found that gender had an effect on orthodontic outcome. Correction seemed to be considered more important by females rather than by males. ${ }^{9}$

Attitude toward oral health and its relation to adherence to oral health preventative behavior is major variable. According to social-learning theory, patients with internal loci of control, who believe that their oral health depends on their own efforts, report increased oral health behaviors. Preventative oral health behaviors includes 
adherence to professional instructions and practicing self-help procedures. ${ }^{25}$ In addition, it was found that more positive the attitude of the parents towards braces, the greater the compliance of the child. What is considered attractive or preferred obviously differs among dental health professionals and lay persons. ${ }^{17}$ In addition; the treatment process itself can also be the source of disruptive and unnecessary agitation. As orthodontic treatment may be uncomfortable, inconvenient, or costly, patients with low health literacy may not fully comprehend the biological reason for orthodontic treatment.

Patient oral hygiene is recognized as an important determinant of orthodontic treatment time and quality of the orthodontic result. It is established that poor patient oral hygiene affects orthodontic treatment outcomes, impacts quality of orthodontic treatment, and prolongs treatment time. It has been stated that each "poor oral hygiene" entry into a patient chart relates to a 0.67 month increase in treatment time. ${ }^{2}$ Reports have shown that 3 or more patient entries for "poor oral hygiene" increase treatment time by 1.2 to 2.2 months. ${ }^{22}$ Other consequences of poor oral hygiene during orthodontic treatment affect the quality of the end result of treatment. Orthodontic treatment with fixed appliances leads to an increased risk of enamel demineralization that is exacerbated in patients with poor oral hygiene. Implementation of a quality oral hygiene control system is beneficial to all orthodontic stakeholders, including, patient, parent, family dentist, and orthodontist. In addition, the use of a "visual analogue" scale for hygiene is a novel approach that has received evidence-bolstered support in application to assessment of other aspects of quality of orthodontic results. ${ }^{35}$

Unlike most other medical or dental care, orthodontic treatment requires that patients return for regular follow-up appointments over a prolonged period of time, lasting up to 2 years or more. It has been shown that missed appointments decrease the likelihood that orthodontic treatment will be completed successfully. ${ }^{28}$ For practitioners, 
failed appointments disrupt the daily schedule and decrease productivity. ${ }^{12}$ Forgetfulness is a common cited excuse given by patients for missing appointments both in general dentistry and in orthodontics. ${ }^{23}$ Other reasons for failing to show up for appointments include having other commitments, inability to get time off and lack of transportation. ${ }^{29}$

Higher rates of appointment failures were found for pediatric dental and orthodontic patients in the United States covered by Medicaid. Having a history of medical debt may also be a predictor of poor appointment attendance. Title XIX of the Social Security Act of 1965 established Medicaid as a form of publicly funded health insurance for the needy. Medicaid was designed to allow participants to use the same medical resources utilized by the general public without prohibitive cost. Both the federal and state governments currently provide funding for this program. Although state governments establish the eligibility requirements and services provided, the federal government maintains a minimum set of standards. The federal government's share of Medicaid expenses is calculated state-by-state and is based upon the state's average per capita income level. This proportion, known as the Federal Medical Assistance Percentage (FMAP), is determined annually and is limited at 83 percent, with a minimum contribution of 50 percent. In 2004, the FMAP varied state-to-state from 50 percent to 77 percent, and averaged 60 percent overall. Medicaid is the largest health insurance provider in the United States. In 2000, 12.3 percent of the population was enrolled in Medicaid, demonstrating the significance of Medicaid as a comprehensive health care provider. The number of Medicaid enrollees in 2002 was estimated to be 39.9 million, with children constituting 46 percent. ${ }^{31}$ Since June 2007, just before the start of the recession, Medicaid enrollment has grown by over 10 million people, over half of whom were children. While enrollment continued to grow reaching 52.6 million by June 2011, 
enrollment growth in the program slowed as the economy started to improve. An additional 2.2 million people enrolled in Medicaid between June 2010 and June 2011 (a growth rate of 4.4 percent). The percentage of uninsured children actually declined slightly during this period, largely due to more children gaining coverage through Medicaid or CHIP. ${ }^{27}$

A large proportion of children in the United States do not receive the dental treatment they require. ${ }^{26}$ Researchers found that 42 percent of Medicaid insured children were in need of some immediate form of dental treatment. This trend in dentistry is echoed in orthodontics. Specifically, in the United States the prevalence of malocclusion severe enough to affect social acceptability or function is estimated at about 15 percent, while an estimated 57 to 59 percent of the population has some orthodontic need, based on the Index of Orthodontic Treatment Need. ${ }^{23}$

Medicaid is the West Virginia's primary health insurance program for low-income children from birth to age 21. In 2010, West Virginia Medicaid covered more than 204,000 children.${ }^{33}$ Children make up the largest number of Medicaid beneficiaries. Almost half of all WV children receive health care and important developmental services through Medicaid. ${ }^{32}$ As of January 2011, 386,449 children were found to live in the state of West Virginia. ${ }^{7}$ Of those 386,449, the total number of children enrolled in Medicaid/ and CHIP included 285,492 recipients. When comparing to a national level, there is an accounted 74,200,000 children living in the United States in $2010 .{ }^{30}$ In $2010,42,175,041$ children were enrolled in Medicaid or CHIP. ${ }^{6}$

While all children enrolled in Medicaid and CHIP have coverage for dental services, ensuring access to these services remains a concern. In Medicaid, children's dental benefits are required through the EPSDT benefit. In CHIP, the children's dental 
benefit became mandatory in 2010 through CHIPRA. The Centers for Medicare and Medicaid Services (CMS) has been working with its Federal and State partners, as well as the dental and medical provider communities. ${ }^{6}$

Data collected by CMS show a clear record of improved children's access to dental care in Medicaid/CHIP. Approximately 40 percent of children in Medicaid received a dental service in 2009 , reflecting a nearly 50 percent increase over the 27 percent of children who received a dental service in 2000. Use of preventive dental services also increased substantially over the same period, with 35 percent of children enrolled in Medicaid receiving a preventive dental service in 2009. This proportion reflected a 61 percent increase over the 21 percent of children receiving a preventive dental service in 2000. These improvements in access occurred during a time period when the number of children enrolled in Medicaid/CHIP and eligible for EPSDT, as reported on the CMS416, grew from 23.5 million to 33.8 million. ${ }^{6}$

The increase in percentage of children receiving a dental service during a period of enrollment growth gives an indication that the dental provider capacity serving children in Medicaid/CHIP expanded during this time. While these improvements are impressive, they remain below the Healthy People 2010 goal of 56 percent of children and adults having a dental visit within a year. Healthy People 2010 is the federal government's agenda to promote health and prevent disease nationwide. The overall goal of the Healthy People 2010 oral health objectives is to prevent and control oral and craniofacial diseases, conditions, and injuries and improve access to related services. Like general health, oral health status in the United States tends to vary based on social and economic conditions. ${ }^{5}$ Through the CMS Oral Health Initiative and implementation of the Oral Health Strategy, CMS is working with States to help them continue to improve access to 
oral health care for Medicaid- and CHIP-enrolled children. The goal is to increase children's utilization of preventive dental services by at least 10 percentage points nationally by 2015 . In addition, there is partnership with the American Dental Association to develop new oral health quality measures focused more on clinical quality and on achieving and measuring improved oral health outcomes. ${ }^{6}$ The percentages of children receiving any dental services from 2000-2009 reported in West Virginia as 33 percent; the national average was 27 percent. The percentage of children receiving preventative dental services from 2000-2009 reported in West Virginia as 27 percent; the national average was 21 percent. $^{6}$

Parental awareness, public and private dental coverage, and availability of dental providers, especially for children receiving Medicaid, are critical factors in children obtaining needed dental care. In addition, there may be no orthodontist in some rural areas. Even though children enrolled in Medicaid are individually entitled under the law to comprehensive preventive and restorative dental services, dental care utilization for this population is low. The reasons for low utilization are many, but a lack of dental providers who participate in Medicaid is a key factor. Few dentists participate in Medicaid - less than half of all active private dentists in some areas. Low reimbursement rates, patient no-shows for appointments, complex forms and burdensome administrative requirements are commonly cited reasons for by dentists not participating in Medicaid. ${ }^{34}$ Patient cooperation, or compliance is essential for successful treatment outcomes in orthodontics. The instructions given to patients pertain to oral hygiene, maintenance of appliances to allow them to function properly, the use of elastics or headgear appliance, and punctuality in keeping appointments. When patients do not follow instructions, an increased time commitment may result for the patient, parent, and the orthodontist. ${ }^{8}$ In 
addition, treatment outcome may be compromised, and in some instances

premature termination of treatment becomes necessary. Improving patient compliance is a challenging and complex problem. Patient compliance with orthodontic instructions tends to decrease over the period of treatment. ${ }^{1}$

The major interest in predicting orthodontic treatment outcome arises from the wide variation in improvement in occlusion achieved. Research indicates a high level of orthodontic failure. This failure involves a huge amount of wasted resources in terms of finance, skills, and time. ${ }^{13}$

\section{Methods and Materials}

This study utilized a retrospective cohort design, which studied pre-existing data only. Approval was granted from West Virginia University’s Institutional Review Board (IRB). All inactive charts for the study were first de-identified. Between 2007 and 2012, there were 278 orthodontic patients at a rural dental office in North Central West Virginia, which were reviewed for this study. This office was a general dentist practicing orthodontics, who was abbreviated as RGP. For each inactive chart, an abstraction form was completed in order to organize all chart entries over the past five years. The form was used to record demographic information, including birth date, age, and gender. Form of payment was assessed, including private insurance, Medicaid, CHIP, and self-pay. If subjects were general patients of RGP, it was notated on the form. Also, previous patients of a deceased orthodontist who then became transfer patients to the dental office were notated. The previous orthodontist was abbreviated as ORTHO. It should be known that several patients were gained after the decease of ORTHO, whose office was within close proximity of the RGP. This situation reflects back to review of lack of providers accepting Medicaid/CHIP patients. The RGP took over the ORTHO practice due to the 
lack of specialists in the area, as well as, the lack of providers accepting the Medicaid/CHIP patients. The visit number in which they transferred to RGP was notated. All dates, oral hygiene ratings, and treatments were recorded from orthodontic treatment beginning to treatment end, which included all appointments with ORTHO and RGP. Occlusion classification and division (if Class II) were notated. Classifications included, Class I, Class II (Divisions I and II), and Class III. The type of appliance was coded by upper bands and brackets only, lower bands and brackets only, full bands and brackets, or an appliance. It should be noted that some patients could have more than one appliance type for this category. For example, some patients may have both an upper expander appliance and also have full bands and brackets. Also, records were occasionally completed more than one time; for example, impressions, photos, and radiographs were sent for approval for an appliance and then completed and sent again for approval of the second phase of treatment including bonding of bands and brackets. Often, new records were completed after the transfer from ORTHO to RGP. For these cases, to gain approval from some of the insurance companies, submission of new records was required.

Travel distance was recorded in order to determine the length of travel distance for each patient to the rural offices. Each appointment was recorded along with notes of treatment, as well as, oral hygiene ratings at each appointment. The oral hygiene ratings were based on a scale from 1-3; 1 being the best oral hygiene, 2 being fair oral hygiene, and 3 being poor oral hygiene. (see appendix B). Note that a rating of 3 , if recorded three times in a row, resulted in a dismissal of treatment due to poor hygiene compliance. Completion and non-completion were recorded. If the subject did not complete the required treatment, the reason was recorded as those being; poor oral hygiene, transfer, 
parent (guardian) request, no response, or removed by patient. If de-banding and debonding procedures occurred, it was notated on the form. (see appendix A).

After the chart abstraction forms were completed, the information was transferred to an Excel spreadsheet. When transferring information to Excel, codes were used for analyzing purposes. (see appendix B). Codes were used to represent gender, occlusion, payment type, oral hygiene, and treatment completion. Patients of ORHTO and RGP were also characterized by codes. For treatment notes, codes were used to describe treatment rendered at each appointment. The reasons for early ending treatment were represented by codes as well. Missing information in this research was coded as 999 , while not applicable information was coded as 888 .

When analyzing the rates of complete versus incomplete treatment by payment type, a Chi Square Fisher's Exact Test was utilized. A Chi Square Fisher's Exact Test was also utilized when analyzing the reason for incomplete treatment by payment type. A logistic regression was performed on the rates of completion versus incompletion by treatment length (in weeks). A one-way ANOVA test was conducted to evaluate the age at beginning of orthodontic treatment with payment type. A Chi Square Fisher's Exact Test was completed when analyzing the rates of completion versus incompletion by gender. A correlation was performed on the rates of completion versus incompletion by travel distance.

A one-way ANOVA test was conducted when analyzing the association of oral hygiene ratings and completion rates. An oral hygiene mean was produced to show the difference between subjects with complete orthodontic treatment versus those subjects with incomplete orthodontic treatment. 


\section{Results}

The Chi Square Fisher's Exact Test comparing completion versus incompletion by payment type showed the two-sided probability p-value resulted in 0.0002 ; these results show that self-pay was more likely to complete treatment than any of the others. The one way ANOVA test showed significant difference between payment types by age at beginning of treatment; $F=4.969$, Sig. $=0.002$. The mean age averages for each group differed; private insurance $=11.95$, self-pay=13.79, Medicaid=10.84, and CHIP=9.00.

The Chi Square Fisher's Exact Test analyzing the reason for incomplete treatment by payment type resulted in a p-value of 0.8359 , which indicates there was no evidence of an association between reason and payment method; although, the Medicaid/CHIP group did give reason 5 (removal of hardware by the patient) more often than the other groups.

The logistic regression on the rates of completion versus incompletion by treatment length (in weeks) resulted in a probability value of $<0.0001$. The results demonstrate that longer treatment length was associated with increased completion rates.

The Chi Square Fisher's Exact Test analyzing the rates of completion versus incompletion by gender resulted in a probability value of 0.5447 . The results show that there was no significant difference between gender and completion rates. more female subjects in this study.

The results of the correlation test show that there was no significant correlation between distance traveled and treatment completion, $\mathrm{r}(278)=.03, \mathrm{p}=.68$. An Analysis of Variance test resulted in a probability value of 0.0450 for completion/incompletion source. The results suggest a significant difference for oral hygiene ratings and completion rates; oral hygiene ratings based on completion status; patients with average oral hygiene ratings of less than or equal to $2 \mathrm{had}$ an increased completion rate. 


\section{Discussion}

The results of this study supported the hypothesis that there would be a significant difference in completion rate among the three payment groups; private insurance, selfpay, Medicaid/CHIP. The unit of the subjects that ranked the highest for not completing treatment was the government funded, Medicaid/CHIP group. Interestingly, the private insurance group was in close percentage of non-completion with the Medicaid/CHIP group. When reflecting back to the review of government-funded programs providing free dental treatment, it can be correlated to the results of this study. Those subjects who were provided orthodontic coverage at no charge were most likely to fail treatment. In other words, those Medicaid/CHIP subjects who were given opportunity to orthodontic treatments took advantage of the free government funds. Results also demonstrate to the statement that private insurance companies, covering a percentage of orthodontic treatment to these Appalachian subjects, also have low completion rates. Individual insurance companies will pay various amounts for orthodontic treatment, unlike Medicaid and CHIP, which cover the entire treatment; however, those subjects utilizing private insurance were still more likely to fail treatment than the self-paying subjects. Those subjects who were paying "out-of pocket" dues to the orthodontic provider possibly had more value of the cost in orthodontic treatment and therefore took more initiative to complete treatment. In addition, the results show that there was a significant difference in payment types when evaluating the age at the beginning of treatment. The self-pay patients began at an older age; therefore, it may be possible that those patients were more mature and also valued orthodontic treatment more than any of the other 
groups who began treatment at a younger age.

The second hypothesis that there would be a significant difference among the three payment groups and the reasons for incompletion was not greatly supported, however, research confirmed that the reason, removal of braces and/or appliance, was the highest for Medicaid and CHIP group. Researchers often question the reasons for failure rates among orthodontic patients; this result in the study elicits that there is a major issue in compliance among Appalachian patients undergoing orthodontic treatment.

An additional result confirmed that the non-completion reason notated as "requested by the parent" was highest in percentage of all groups with the exception of self-paying patients when studying the reasons for failing treatment. The self-pay group's was highest in percentage for "no response." The term "no response" meant that numerous attempts were made to contact the patient/parent with no response in return; resulting in no communication or further appointments made. This confirms that Appalachia parents are also in need for an outreach. As stated in a JADA article, Oral Health Disparities in Appalachia, it was hypothesized that there would be less use of orthodontic services in a West Virginia sample and similar need, but lower demand, for these services compared with levels in other studies and populations. ${ }^{19}$ The results of this previous study indicated that there may generational effects in that the trend to receive orthodontic care was higher in adolescents than in their parents and that treatment need among Appalachian adolescents was not greater than, but similar to, that found nationally. ${ }^{19,20}$ It was concluded that the level of treatment demand still was significantly 
lower than published norms, which may be related to oral health values. ${ }^{19}$ This lower demand may translate into less pursuit of oral health care services to improve occlusion later in life, which may be associated with poorer functionality and with lower oral health quality of life. ${ }^{19}$ This may be the case with this current study as well, for the parents are the reasons for the child to not complete the necessary orthodontic treatment, which means ending treatment early before the correct occlusion is reached. With these results and the results of Oral Health Disparities in Appalachia, it signifies that many parents do not find orthodontic care a high priority. This disparity in Appalachia could be intergenerational and have an effect on those subjects who removed the braces and/or appliance. Orthodontic care is not of importance to the parents, then it becomes a low priority to the children; therefore, they fail to complete treatment by removing the unwanted hardware themselves.

The results of this study supported the hypothesis that there would be correlation between completion rate and length of orthodontic treatment. The results confirmed that the longer the subjects were in treatment, the more likely they were to complete the full orthodontic treatment. It should be notated that individual variation is the reality of orthodontic treatment time. The more simple, limited orthodontic cases can often be completed in 8 to 12 months, where as the more severe, complex cases can often be treated in approximately 36 months.

The results did not support the hypothesis that completion rate and distance traveled would be related; there was no significant correlation between distance traveled and treatment completion. 
Furthermore, gender was found to have no significant difference in completion rates; therefore, it may be stated that females and males of Appalachia have no difference in probability completing orthodontic treatment.

Lastly, the results supported the hypothesis that a significant difference would be found involving oral hygiene ratings and completion rates. Results illustrated patients that had better oral hygiene, receiving rating values of less than or equal to 21 had a higher expectancy to complete orthodontic treatment.

\section{Limitations \& Recommendations}

One limitation of this project could be the homogeneity of the sample. The inclusion criteria for participation were limited to patients of one orthodontic office in rural, North Central West Virginia. This could lead to concerns about the generalization of the results to additional areas in Appalachia.

An additional limiting factor when comparing the reasons for non-completion was the category notated as "no response." For this group, contact was attempted after 
multiple broken or cancelled appointments. Therefore, it was unknown if those subjects completed treatment at another office. Those patients who transferred from ORTHO to RGP may have also extended treatment length due to the time lapse between transfer.

For a future suggestion, researchers may find significance in analyzing the types of appliances compared to completion rates. It would be valuable to find differences in compliance and completion rates by appliance type. It would also be beneficial to study the association of occlusion classification and treatment length and extraction versus nonextraction. The association could then be evaluated with orthodontic compliance and completion rates.

A further suggestion for future research would be to analyze the number of broken and cancelled appointments. By depicting this data, researchers would be able to recognize the effects of appointment compliance during orthodontic treatment with completion rates.

A final note to add is the research end date, May 31, 2012. Patients ending treatment (becoming inactive) were not recorded due to completion of research.

\section{Conclusions}

In agreement with the previous research completed in Appalachia, culturally sensitive psychoeducational and psychosocial interventions may be needed to inculcate positive oral values that can help address these orthodontic disparities. ${ }^{19}$ In order to instill the value of orthodontic treatment, including the benefits on reaching an ideal occlusion, these interventions must be addressed to both the parents and the children undergoing orthodontic treatment at the beginning of treatment, and continue throughout their time in orthodontic care. Dental professionals may need to educate more on the purpose of orthodontics to the patient and the parent, for they may have a different view on an 
"ideal" occlusion. Appalachian families may not fully understand the necessity of changing one's occlusal status for not only esthetic, but for functional reasons.

Those individuals utilizing free dental programs such as Medicaid and CHIP may need more education on the services that are provided to them free of charge. Interventions may be advantageous at local DHHR facilities, as well as, the orthodontic offices providing services. Values on compliance may be internalized if both the patient and parent(s) were informed about these free programs in comparison with actual cost of treatment if they were to pay for it themselves. A contract in place between provider and patient is essential. If the government programs could also formulate a contract of service with compliance and requirements set by the orthodontic provider, the completion rates may increase significantly. Providing free services often results in coverage abuse; hence, modifications must be made to improve the completion rates among orthodontic patients undergoing treatment in Appalachia.

Oral hygiene ratings proved an influence on completion rates among the Appalachian orthodontic patients. Those patients who earn better oral hygiene ratings, 1 or 2, have a higher expectation to complete treatment compared to those patients who earn poorer oral hygiene ratings, 2 or 3 . These results shows similarity with previous research, patient oral hygiene among the Northern Appalachian patients is an important determinant of orthodontic completion results; poor patient oral hygiene affects orthodontic treatment outcomes. ${ }^{22}$ A rating scale system is a good assessment tool in determining the patient's home-care, while also indicating the condition of the teeth and surrounding tissues during orthodontic treatment. Parental and patient involvement with proper oral hygiene practices is essential to satisfactory orthodontic outcomes. 


\section{Bibliography}

1. Albino J., Lawrence S., Nash L., \& Tedesco L.1991. Cooperation of adolescents in orthodontic treatment. Journal of Behavioral Medicine. 144: 53-70.

2. Beckwith F., Ackerman R., Cobb C., \& Tira D. 1999. An evaluation of factors affecting duration of orthodontic treatment. American Journal of Orthodontics and Dentofacial Orthopedics. 115 (4): 439-447.

3. Bos A., Hoogstraten J., Prahl-Anderson B. 2003. Expectations of treatment and satisfaction with dentofacial appearance in orthodontic patients. American Journal of Orthodontics and Dentofacial Orthopedics. 123 (2): 127-132.

4. Bos A., Hoogstraten J., \& Prahl-Andersen B. 2003. On the use of personality characteristics in predicting compliance in orthodontic practice. American Journal of Orthodontics and Dentofacial Orthopedics. 123 (5): 568-570.

5. Centers for Disease Control and Prevention. Behavioral Risk Factor Surveillance System: Turning Information Into Health. 2006. Atlanta: National Center for Chronic Disease Prevention and Health Promotion, U.S. Dept. of Health and Human Services; 2006. 21 Jan. 2012. www.cdc.gov/brfss/.

6. Centers for Medicare \& Medicaid Services. 2011. Use of dental services in Medicaid and CHIP. www.cms.gov/. 19 June 2012. 
7. Children's Defense Fund. Children in West Virginia. www.childrensdefense.org. 23 June 2012.

8. Clark, J. 1976. Oral Hygiene in orthodontic practice: motivation, responsibilities, and concepts. American Journal of Orthodontics 69: 72-82.

9. Coyne R., Woods M., \& Abrams R. 1999. The community and orthodontic care. Part II: Community-perceived importance of correcting various dentofacial anomalies. Part III: Community perception of the importance of orthodontic treatment. Australian Orthodontic Journal. 15 (5): 289-301.

10. DiMatteo R., Donald C., Hays R., Ordway, L., Kravitz R., McGlynn E., Kaplan S., \& Rogers W. 1993. Physicians' characteristics influence patients' adherence to medical treatment: Results from the Medical Outcomes Study. 12 (2): 93-102.

11. Feil, P., Grauer, J., Gadburty-Amyot C., Kula K. \& McCunnif M. 2002. Intentional use of the hawthorne effect to improve oral hygiene compliance in orthodontic patients. Journal of Dental Education. 66 (10): 1129-1134. 
12. Horsley B., Lindauer S., Shroff B., Tufekci E., Akbubaker A., and Fowler C. 2007. Appointment keeping behavior of Medicaid vs non-Medicaid orthodontic patients. American Journal of Orthodontics and Dentofacial Orthopedics. 132: 4953.

13. Jewair, T., Suri S., \& Tompson B. 2011. Predictors of adolescent compliance with oral hygiene instuctions during two-arch multibracket fixed orthodontic treatment. Angle Orthodontist. 81 (3): 525-531.

14. Joury E., Marcenes W., \& Johal A. 2011. The role of psychosocial factors in predicting orthodontic treatment outcome at the end of 1 year of active treatment. European Journal of Orthodontics. 10: 1093.

15. Kiyak HA. 1981. Comparison of esthetic values among Caucasians and PacificAsians. Community Dentistry and Oral Epidemiology. 9 (5): 219-223

16. Kiyak H.A. 2006. Cultural and psychological influences on treatment demand. Seminars in Orthodontics. 6: 242-248.

17. Kiyak H.A., McNeil R.W., \& West R.A. 1985. The emotional impact of orthognathic surgery and conventional orthodontics. American Journal of Orthodontics and Dentofacial Orthopedics. 88 (3): 224-234. 
18. Krishnon, V., Davidovitch Z. 2007. Integrated Clinical Orthodontics. John Wiley and Sons. 1-498.

19. Martin, C.A., McNeil D.W., Crout, R.J., Ngan, P.W., Weyant, R.J., Heady, H.R., Marazita, M.L. 2008. Oral Health Disparities in Appalachia. The Journal of the American Dental Association. 139: (5): 598-604.

20. McNeil D.W., Crout R.J., Lawrence S.M., Shah P, \& Rupert N. 2004. Oral health values in Appalachia: specific dental-related fatalism. Journal of Dental Research 83: (A): 203.

21. Patel, V. 1989. Non-completion of orthodontic treatment, a study of patient and parental factors contributing to the discontinuation in the hospital service and specialist practice. Thesis, University of Wales. 33: 83-85.

22. Profit W.R., Fields H.W., \& Moray L.J. 1998. Prevalence of malocclusion and orthodontic treatment need in the United States: estimates from the NHANES III survey. International Journal of Orthodontics \& Orthognathic Surgery. 13 (2): 97106.

23. Richardson A. 1998. Failed appointments in an academic orthodontic clinic. British Dental Journal. 184: 612-615. 
24. Skidmore K., Brook K., Thomson W., \& Harding W. 2006. Factors influencing treatment time in orthodontic patients. American Journal of Orthodontics and Dentofacial Orthopedics. 129 (2): 230-238.

25. Tedisco, L., Keffer, M., \& Fleck-Kandath C. 1991. Self-efficacy, reasoned action, and oral health behavior reports: A social cognitive approach to compliance. Journal of Behavioral Medicine. 14 (4): 341-355.

26. The Kaiser Commission on Medicaid and the Uninsured. 2008. Filling an Urgent Need: Improving Children's Access to Dental Care in Medicaid and SCHIP Report. [Brochure].

27. The Kaiser Commission on Medicaid and the Uninsured. 2012. Medicaid Enrollment: June 2011 Data Snapshot. Publication 8050.

28. Trenouth, M. 2003. Do failed appointments lead to discontinuation of orthodontic treatment? The Angle Orthodontist. 73 (1): 51-55.

29. Trenouth M. \& Hough A. 1991. Reasons for broken and cancelled appointments in a British orthodontic clinic. Journal of Clinical Orthodontics. 25: 115-120.

30. U.S. Consensus Bureau. Current Population Reports, Estimates of the population of the United States. www.childstats.gov. 23 June 2012. 
31. U.S. Department of Health and Human Resources. Medicaid Program-General Information: Technical Summary. 2007. http://cms.bbs.gov/MedicaidGenInfo/03_TechnicalSummary.asp. June 2012.

32. West Virginia Bureau for Medical Services. Services for individuals under 21. www.dhhr.gov/bms/. 19 June 2012.

33. West Virginia Bureau for Public Health, Division of Health Statistics. http://wvdhhr.org. 19 June 2012.

34. West Virginia Department of Health and Human Resources. West Virginia Oral Health Plan 2010-2015. http://www.wvdhhr.org/mcfh/icah/wv_oral_health_plan_2010.pdf. 10 July 2012.

35. Zachrisson, B.U. 1971. Caries incidence and orthodontic treatment with fixed appliances. European Journal of Oral Sciences. 79(2): 183-192 


\section{Appendix A}

Factors Affecting Orthodontic Adherence in Appalachia

Chart Abstraction Form

PARTICIPANT ID \#:

DOB:

GENDER: $M$ F

DISTANCE BETWEEN PATIENT HOME AND ORTHODONTIC OFFICE (IN

MILES):

TYPE OF PAY: DATE OF STUDY VISIT:

PATIENT OF RGP: Y N

PREVIOUS PATIENT OF ORTHO: Y N

VISIT \# FOR TRANSFER FROM ORTHO TO RGP:

OCCLUSION:

APPLIANCE(S):

TOTAL TREATMENT LENGTH:

TOTAL \# OF APPOINTMENTS:

TREATMENT COMPLETION: Y N

IF NO, WAS A DEBAND PERFORMED? Y N

REASON FOR EARLY DEBAND:

VISIT \#:

\begin{tabular}{|c|c|}
\hline Date & OHI Rating \\
\hline & \\
& \\
\hline
\end{tabular}

Treatment Notes:

VISIT \#:

\begin{tabular}{|c|c|}
\hline Date & OHI Rating \\
\hline & \\
& \\
\hline
\end{tabular}

Treatment Notes:

(All visits during orthodontic treatment in chart will be recorded) 
Gender:

\section{Appendix B}

1: Male

2: Female

Payment:

1: Private Insurance

2: Self-pay

3: Medicaid

4: CHIP

General Patient of RGP:

1: Yes

2: No

Previous Orthodontic Patient of ORTHO:

1: Yes

2: No

Occlusion:

1: Class I

2: Class II

2a: Class II, Division I

2b: Class II, Division II

3: Class III

Appliance:

1: Upper arch bands/brackets only

2: Lower arch bands/brackets only

3: Full (both arches) bands and brackets

4: Device

Complete/Incomplete:

1: Complete

2: Incomplete

Incomplete Reason:

1: Poor oral hygiene

2: Transfer

3: Parent (Guardian) request

4: No response

5: Removed by patient 
For Incomplete - Deband/Debond performed

1: Yes

2: No

Oral Hygiene Rating (OHI):

1: Good oral hygiene; Represents a minimal amount of plaque on the teeth.

2: Fair oral hygiene; Represents a moderate amount of soft deposits on the teeth.

3: Poor oral hygiene; Represents an abundance of soft matter on the teeth.

Treatment:

1: Records (radiographs, photographs, \& impressions)

2: Placement of separators

3: Banding and Bonding (braces and/or device)

4: Ligature retie

5: Device adjustment

6: Deband/Debond (braces and/or device)

7: Cement removal (if braces were removed by patient)

8: Cancelled appointment

9: Broken appointment

10: Replace/Recement (band, brackets, and/or device)

*Missing information: 999

*Not applicable: 888 


\section{Appendix C}

\begin{tabular}{|c|c|c|c|c|c|c|c|}
\hline SUBJECT & BIRTHDATE & AGE BEGIN & AGE END & $\begin{array}{l}\text { TX LENTH } \\
\text { (WKS) }\end{array}$ & DISTANCE & GENDER & GEN PT \\
\hline 1 & $6 / 5 / 93$ & 13 & 15 & 143 & 29.6 & 1 & 2 \\
\hline 2 & $5 / 30 / 94$ & 9 & 13 & 196 & 2 & 2 & 2 \\
\hline 3 & $10 / 22 / 91$ & 8 & 17 & 470 & 38.3 & 1 & 2 \\
\hline 4 & $7 / 18 / 92$ & 13 & 17 & 175 & 40.4 & 2 & 2 \\
\hline 5 & $4 / 10 / 95$ & 9 & 15 & 295 & 28 & 1 & 2 \\
\hline 6 & $6 / 16 / 96$ & 10 & 14 & 190 & 44.3 & 1 & 2 \\
\hline 7 & $1 / 29 / 98$ & 7 & 12 & 275 & 28.9 & 2 & 2 \\
\hline 8 & $1 / 1 / 93$ & 14 & 16 & 102 & 6 & 2 & 1 \\
\hline 9 & $10 / 1 / 92$ & 14 & 14 & 88 & 5.2 & 2 & 2 \\
\hline 10 & $5 / 22 / 58$ & 49 & 53 & 204 & 57.2 & 2 & 2 \\
\hline
\end{tabular}

\begin{tabular}{|c|c|c|c|c|c|c|}
\hline PREV PT & $\begin{array}{l}\text { TRANSFER } \\
\text { VISIT \# }\end{array}$ & OCCLUSION & $\begin{array}{l}\text { APPLIANCE } \\
1\end{array}$ & $\begin{array}{l}\text { APPLIANCE } \\
2\end{array}$ & PAY & $\mathrm{COM} / \mathrm{INC}$ \\
\hline 1 & 5 & $2 \mathrm{~A}$ & 3 & 888 & 4 & 1 \\
\hline 1 & 25 & $2 \mathrm{~A}$ & 3 & 888 & 3 & 1 \\
\hline 1 & 30 & $2 \mathrm{~A}$ & 3 & 888 & 1 & 1 \\
\hline 1 & 5 & 1 & 3 & 888 & 3 & 1 \\
\hline 1 & 8 & $2 \mathrm{~A}$ & 3 & 4 & 3 & 1 \\
\hline 1 & 3 & $2 \mathrm{~A}$ & 3 & 888 & 2 & 1 \\
\hline 1 & 8 & $2 \mathrm{~A}$ & 3 & 888 & 3 & 1 \\
\hline 2 & 888 & 3 & 3 & 888 & 3 & 2 \\
\hline 2 & 888 & $2 \mathrm{~A}$ & 4 & 888 & 1 & 2 \\
\hline 2 & 888 & $2 \mathrm{~A}$ & 4 & 888 & 1 & 2 \\
\hline
\end{tabular}

\begin{tabular}{|c|c|c|c|c|c|c|c|}
\hline I-DEBAND? & I-REASON & $\begin{array}{l}\text { REASON- } \\
\text { NOTES }\end{array}$ & 1-DATE & 1-OHI & 1-TX A & 1-TX B & 1-TX C \\
\hline 888 & 888 & 888 & $6 / 21 / 06$ & 999 & 1 & 888 & 888 \\
\hline 888 & 888 & 888 & $12 / 17 / 03$ & 999 & 1 & 888 & 888 \\
\hline 888 & 888 & 888 & $11 / 3 / 99$ & 999 & 1 & 888 & 888 \\
\hline 888 & 888 & 888 & $6 / 28 / 06$ & 999 & 1 & 888 & 888 \\
\hline 888 & 888 & 888 & $3 / 22 / 05$ & 999 & 1 & 888 & 888 \\
\hline 888 & 888 & 888 & $11 / 10 / 06$ & 1 & 1 & 888 & 888 \\
\hline 888 & 888 & 888 & $10 / 5 / 05$ & 999 & 1 & 888 & 888 \\
\hline 1 & 3 & $\begin{array}{l}\text { child } \\
\text { complaint }\end{array}$ & $2 / 1 / 07$ & 1 & 1 & 888 & 888 \\
\hline 2 & 4 & no comm & $2 / 16 / 07$ & 1 & 1 & 888 & 888 \\
\hline 2 & 4 & no comm & $11 / 7 / 07$ & 1 & 1 & 888 & 888 \\
\hline
\end{tabular}




\section{Tables and Figures}

\section{Table 1.}

Contingency Analysis of Complete/Incomplete [By Payment Type]

PAY By COM/INC

\begin{tabular}{|l|r|r|r|}
\hline Count & 1 & 2 & \\
Row \% & & & \\
\hline 1 & 7 & 12 & 19 \\
PrivIns & 36.84 & 63.16 & \\
\hline 2 & 25 & 9 & 34 \\
Self-pay & 73.53 & 26.47 & \\
\hline 3 & 75 & 144 & 219 \\
Mcaid & 34.25 & 65.75 & \\
\hline 4 & 2 & 4 & 6 \\
CHIP & 33.33 & 66.67 & \\
\hline & 109 & 169 & 278 \\
\hline
\end{tabular}

\section{Tests}

$\begin{array}{rrrr}\mathbf{N} & \text { DF } & \text {-LogLike } & \text { RSquare (U) } \\ 278 & 3 & 9.4543667 & 0.0508\end{array}$

Test

Likelihood Ratio

Pearson

\section{ChiSquare}

18.909

19.196
Prob $>$ ChiSq

$0.0003^{*}$

$0.0002^{*}$

Note: Self-pay were more likely to complete treatment than any of the others.

Fisher's Exact Test:

Table Probability Two-sided Prob

(P)

8.581e-7 $0.0002 *$ 


\section{Table 2.}

Contingency Analysis of Incomplete-Reason

[By Payment Type]

Payment Type By Incomplete-Reason

\begin{tabular}{|l|r|r|r|r|r|r|}
\hline $\begin{array}{l}\text { Count } \\
\text { Row \% }\end{array}$ & 1 & 2 & 3 & 4 & 5 & \\
\hline Medic/CHIP & 35 & 16 & 46 & 33 & 18 & 148 \\
& 23.65 & 10.81 & 31.08 & 22.30 & 12.16 & \\
\hline Priv Ins & 3 & 2 & 4 & 3 & 0 & 12 \\
& 25.00 & 16.67 & 33.33 & 25.00 & 0.00 & \\
\hline Self Pay & 1 & 1 & 2 & 4 & 1 & 9 \\
& 11.11 & 11.11 & 22.22 & 44.44 & 11.11 & \\
\hline & 39 & 19 & 52 & 40 & 19 & 169 \\
\hline
\end{tabular}

Tests

$\begin{array}{rrrr}\mathbf{N} & \text { DF } & \text {-LogLike } & \text { RSquare (U) } \\ 169 & 8 & 2.7662928 & 0.0107\end{array}$

Test

Likelihood Ratio

ChiSquare

5.533

Prob $>$ ChiSq

Pearson

4.410

0.6994

0.8184

Warning: $20 \%$ of cells have expected count less than 5, ChiSquare suspect.

Fisher's Exact Test:

Table Probability Two-sided Prob

(P) $\quad \leq \mathbf{P}$

3.769e-5 $\quad 0.8359$

Note: The p-value immediately above (0.8359) indicates that there is no evidence of an association between reason and payment method even though the Medicaid/CHIP group does seem to give reason \# 5 (removed by patient) more often than the other groups. 


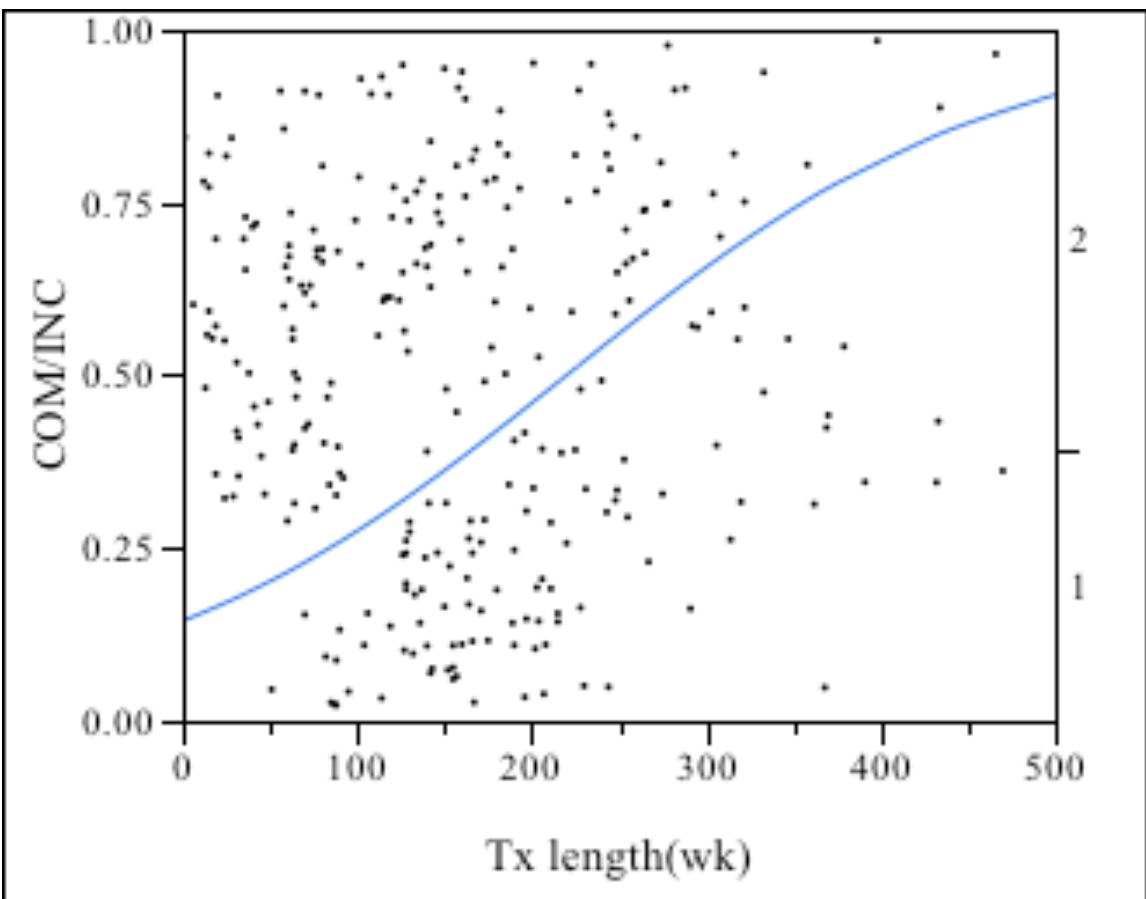

Figure 1. Fit Y by X Group:_Logistic Fit of Complete/Incomplete [By Tx length(wks)]

\section{Whole Model Test}

$\begin{array}{lrrrr}\text { Model } & \text {-LogLikelihood } & \text { DF } & \text { ChiSquare } & \text { Prob>ChiSq } \\ \text { Difference } & 17.51495 & 1 & 35.0299 & <.0001^{*} \\ \text { Full } & 168.65392 & & & \\ \text { Reduced } & 186.16887 & & & \end{array}$

Note: Longer treatment length is associated with increased completion rate.

RSquare (U)

$$
0.0941
$$

$\mathrm{AICc}$

341.351

BIC 348.563

Observations (or Sum Wgts)

278

\section{Measure}

Entropy RSquare

Generalized R-Square

Mean $-\log p$

RMSE

Mean Abs Dev

Misclassification Rate $\mathrm{N}$

\section{Training Definition}

0.0941 1-Loglike(model)/Loglike(0)

$0.1604\left(1-(\mathrm{L}(0) / \mathrm{L}(\operatorname{model}))^{\wedge}(2 / \mathrm{n})\right) /\left(1-\mathrm{L}(0)^{\wedge}(2 / \mathrm{n})\right)$

$0.6067 \sum-\log (\rho[\mathrm{j}]) / \mathrm{n}$

$0.4595 \sqrt{ } \sum(y[j]-\rho[j])^{2} / n$

$0.4203 \sum \mid \mathrm{y}[\mathrm{j}]-\rho[\mathrm{j}] / / \mathrm{n}$

$0.3921 \sum(\rho[j] \neq \rho \mathrm{Max}) / \mathrm{n}$ 
Table 3.

Contingency Analysis of Complete/Incomplete [By GENDER]

GENDER By COM/INC

\begin{tabular}{|l|r|r|r|}
\hline $\begin{array}{l}\text { Count } \\
\text { Row \% }\end{array}$ & 1 & 2 & \\
\hline 1 & 45 & 76 & 121 \\
\hline 2 & 37.19 & 62.81 & \\
\hline & 64 & 93 & 157 \\
\hline & 40.76 & 59.24 & \\
\hline
\end{tabular}

Tests

$\begin{array}{rrrr}\mathbf{N} & \text { DF } & \text {-LogLike } & \text { RSquare (U) } \\ 278 & 1 & 0.18343626 & 0.0010\end{array}$

$\begin{array}{lrr}\text { Test } & \text { ChiSquare } & \text { Prob }>\text { ChiSq } \\ \text { Likelihood Ratio } & 0.367 & 0.5447 \\ \text { Pearson } & 0.366 & 0.5451\end{array}$

Fisher's Prob Alternative Hypothesis

Exact Test

Left $\quad 0.3155 \mathrm{Prob}(\mathrm{COM} / \mathrm{INC}=2)$ is greater for $\mathrm{GENDER}=1$ than 2

Right $0.7668 \mathrm{Prob}(\mathrm{COM} / \mathrm{INC}=2)$ is greater for GENDER=2 than 1

2-Tail $\quad 0.6204 \mathrm{Prob}(\mathrm{COM} / \mathrm{INC}=2)$ is different across GENDER

Note: There is approximately $3 \%$ more likelihood that females will complete treatment more so than males. 


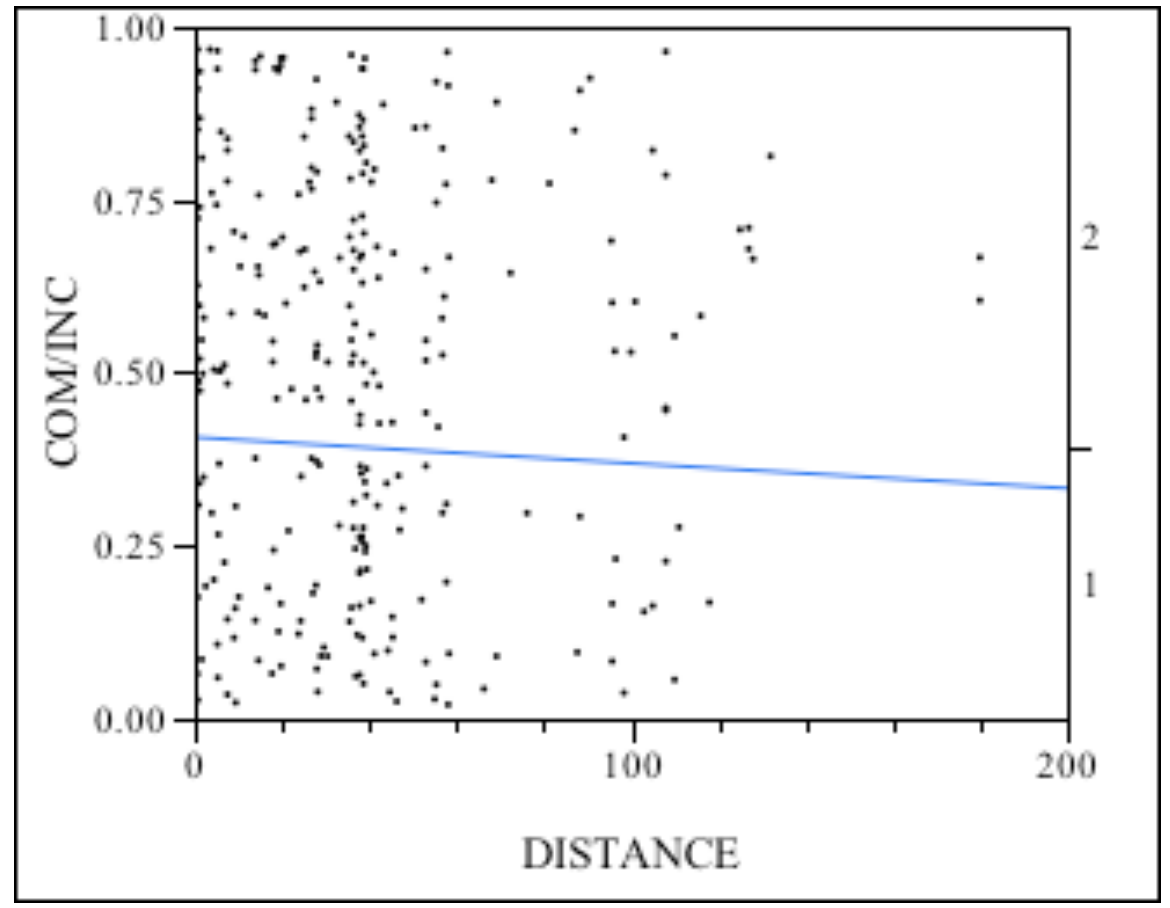

Figure 2. Logistic Fit of Complete/Incomplete [By DISTANCE]

Whole Model Test

Model

Difference

Full

Reduced
-LogLikelihood

0.08787

186.08099

186.16887
RSquare (U)

AICc

$\mathrm{BIC}$

Observations (or Sum Wgts)
0.0005

376.206

383.417
Measure

Entropy RSquare

Generalized R-Square

Mean -Log $p$

RMSE

Mean Abs Dev

Misclassification Rate $\mathrm{N}$
Training Definition

0.0005 1-Loglike(model)/Loglike(0)

$0.0009\left(1-(\mathrm{L}(0) / \mathrm{L}(\operatorname{model}))^{\wedge}(2 / \mathrm{n})\right) /\left(1-\mathrm{L}(0)^{\wedge}(2 / \mathrm{n})\right)$

$0.6694 \sum-\log (\rho[\mathrm{j}]) / \mathrm{n}$

$0.4881 \sqrt{ } \sum(y[j]-\rho[j])^{2} / n$

$0.4764 \sum|\mathrm{y}[\mathrm{j}]-\rho[\mathrm{j}]| / \mathrm{n}$

$0.3921 \sum(\rho[\mathrm{j}] \neq \rho \mathrm{Max}) / \mathrm{n}$

$278 \mathrm{~N}$ 
Table 4.

Oneway Analysis of Mean (Hygiene) By Complete/Incomplete:

$\begin{array}{lrr}\text { Difference } & 0.136872 \text { t Ratio } & 2.014118 \\ \text { Std Err Dif } & 0.067957 \text { DF } & 273 \\ \text { Upper CL Dif } & 0.270658 \text { Prob }>|t| & 0.0450^{*} \\ \text { Lower CL Dif } & 0.003087 \text { Prob }>\mathrm{t} & 0.0225^{*} \\ \text { Confidence } & 0.95 \text { Prob }<\mathrm{t} & 0.9775\end{array}$

Analysis of Variance

$\begin{array}{lrrrrr}\text { Source } & \text { DF } & \begin{array}{r}\text { Sum of } \\ \text { Squares }\end{array} & \text { Mean Square } & \text { F Ratio } & \text { Prob }>\text { F } \\ \text { COM/INC } & 1 & 1.232634 & 1.23263 & 4.0567 & 0.0450^{*} \\ \text { Error } & 273 & 82.951985 & 0.30385 & & \\ \text { C. Total } & 274 & 84.184619 & & & \end{array}$

\section{Means for Oneway Anova}

$\begin{array}{lrrrrr}\text { Level } & \text { Number } & \text { Mean } & \text { Std Error } & \text { Lower 95\% } & \text { Upper 95\% } \\ 1 & 109 & 1.57303 & 0.05280 & 1.4691 & 1.6770 \\ 2 & 166 & 1.70990 & 0.04278 & 1.6257 & 1.7941\end{array}$


Table 5.

Dependent Variable: Age Begin - Univariate Analysis of Variance

\begin{tabular}{|l|l|l|l|}
\hline Pay & Mean & Std Deviation & $\underline{N}$ \\
\hline 1 & 11.95 & 9.246 & 19 \\
\hline 2 & 13.79 & 8.481 & 34 \\
\hline 3 & 10.84 & 2.616 & 219 \\
\hline 4 & 9.00 & 2.966 & 6 \\
\hline Total: & 11.24 & 4.554 & 278 \\
\hline
\end{tabular}

$F=4.969 * ;$ Sig. $=.002 *$ 
Figure 3. *fix

\section{Partition for Complete and Incomplete:}

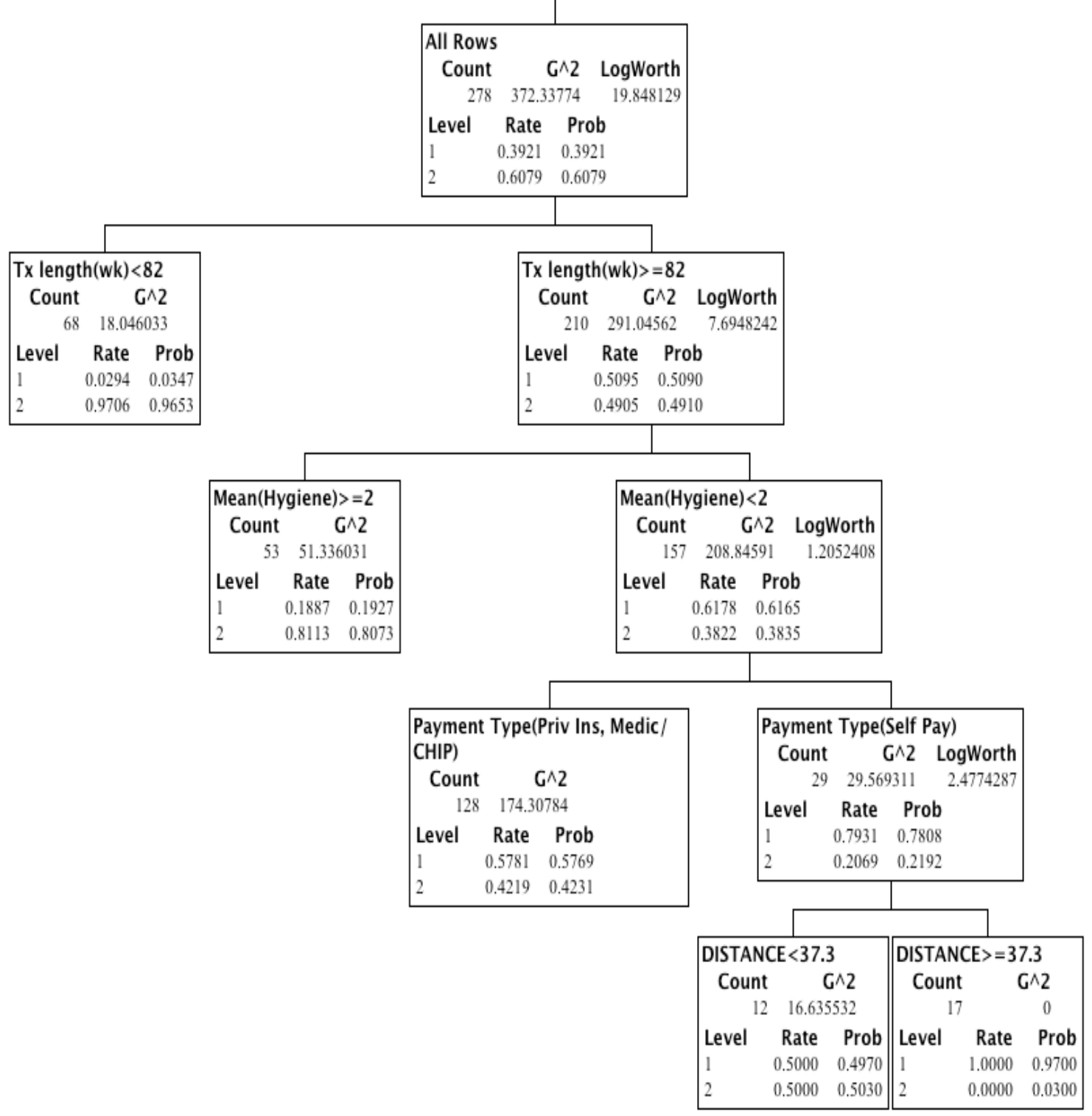

